\title{
El diseño como soporte de la identidad en la Cultura Clásica Contemporánea
}

Carolina González Miranda ${ }^{1}$

RECIBIDO: 08.01.2015 / ACEPTADO: 16.03.2015

\section{Resumen}

La identidad es una cualidad que nos define, con la que expresamos nuestra forma de hacer y crear. Esa identidad es herencia directa de la cultura en la que hemos nacido, vivido y ha crecido nuestra personalidad; y cuyo bagaje se han transmitido a través de las generaciones. El diseño es cultura, ya que expresa valores y cualidades. Es la identidad ese sello de personalidad, que ha dado lugar a una Cultura Clásica Contemporánea, constituida no solo por los países herederos directos de la cultura del Mediterráneo Clásico, España, Italia y Portugal, sino también toda América. Es el diseño el soporte donde se muestra la identidad de la Cultura Clásica Contemporánea.

Palabras clave: identidad, diseño industrial, cultura clásica contemporánea, cultura, artesanía.

\section{Design as the identity support in Classic Contemporary Culture}

\section{Abstract}

The identity defines us. This identity is inherited through the generations and the way of how things are designed relies on it for creating. Design is a manifestation of culture. The Classic Contemporary Culture is the identity that marks the personality of the way of designing not only in its direct heirs, which are the countries that comprise the Classic Mediterranean Culture, but also throughout America. This identity, though its miscegenation capability, is a competitive alternative to other identities.

Keywords: identity, industrial design, classic contemporary culture, culture.

La cultura forma parte de nuestra personalidad, heredada con el paso de los años, y trasmitida a través de las generaciones. Dicha cultura mantiene su esencia y se adapta a los nuevos tiempos, creando riqueza etnológica, diversidad y marcando una identidad propia. La cultura impregna la forma de ser de la gente, hecho que se ve en las costumbres cotidianas, en los actos sociales y económicos, en las fiestas, etc.

A través del diseño se expresan cualidades, formas, valores y signos que definen una cultura, donde se refleja la identidad de lo que se denomina la Cultura Clásica Contemporánea². Esta cultura clásica actual pertenece tanto a los países mediterráneos y Portugal, como a los países de Latinoamérica y América del Norte, no siendo la lengua latina ${ }^{3}$ común la única causa de semejanza. 
Las llegadas al Nuevo Mundo ya trasladaron esa lengua latina común, que no ha hecho más que favorecer las relaciones entre los países a lo largo de los años.

Aunque difícil de evaluar, se reconoce generalmente a los factores lingüísticos y culturales un papel de gran importancia en las relaciones de España con América Latina, y en especial con los países hispanohablantes de esta región. Esto se advierte entre otras cosas en la evolución reciente de los intercambios sociales (migraciones) y económicos (inversiones) entre ambas partes ${ }^{4}$.

La Cultura Clásica Contemporánea que se expone, común a países mediterráneos de la vieja Europa y los países del Nuevo Mundo, muestra características que van más allá de la unión lingüística. Coinciden en la predisposición a la abertura de mente y en un mestizaje que ha marcado el desarrollo de su propia identidad.

Otras características son el carácter reivindicativo de la sociedad que la forma, el uso de la artesanía, de colores alegres y materiales naturales. La tendencia a diseñar con una estética con formas suaves y con recuerdos a otras culturas.

Esa misma identidad colectiva es fruto de los vínculos inseparables que se han establecido incluso con las culturas de pueblos de aislados rincones del mundo. Con ello se ha creado una identidad con alto valor estético que se diferencia de la uniformidad propia de otras sociedades. Esto hace que la Cultura Clásica Contemporánea definida ${ }^{5}$ tenga mayor fuerza y conciencia de su procedencia y una visión de futuro como salto a un mercado más competitivo e innovador, a través del conocimiento y el uso del diseño como herramienta fundamental.

El diseño como herramienta de difusión, donde se muestran los caracteres de dicha identidad, se hace necesario como promotor de la identidad de la propia cultura. Por ello, a través de la investigación en el diseño se crea la necesidad de una definición, catalogación y una estrategia de comunicación y difusión del diseño. Con ello se exteriorizará la riqueza de trabajos autóctonos.

El diseño muestra, a través de sus creaciones, las connotaciones culturales externas a las que la propia identidad ha estado abierta. A través del diseño se expresan ideas y pensamientos, siendo América Latina donde se creó ese encuentro y amalgamiento de las distintas culturas del mundo ${ }^{6}$, y es por tanto en sus diseños donde más se expresa su identidad.

Todo el diseño es comunicación, porque interfiere en las percepciones humanas. El diseño no está fuera de la persona, vive en él, y el artista lo transmite ${ }^{8}$.

Cada receptor, y cada cual a su manera, tiene algo que podríamos llamar "filtros" a través de los cuales deberá pasar el mensaje para ser definido; uno de ellos es de carácter sensorial. Por ejemplo, un daltónico no percibe determinados colores y, por tanto, los mensajes basados exclusivamente en el lenguaje cromático se ven, en su caso, alterados o anulados. Otro filtro podría llamarse "operativo" o dependiente de las características fisiopsicológicas del receptor. Por ejemplo, está claro que un niño de tres años analizará un mensaje de una manera muy diferente de la de un adulto. Un tercer filtro, que podría llamarse "cultural", dejará pasar solo aquellos mensajes que el recetor reconoce; es decir, aquellos que forman parte de su universo cultural. Por ejemplo, muchos 
occidentales no reconocen la música oriental como tal porque no se corresponde con sus normas culturales; para ellos la música "debe ser" la que siempre han conocido, ninguna otra".

Es la identidad lo que nos diferencia del resto y hace que nuestra personalidad quede plasmada en cualquier soporte. Es esa materialización del diseño donde se reflejan las características de la identidad, más allá del concepto de belleza que pueda llevar la actividad plástica.

La belleza no puede definirse, ya que existen cosas bellas y cosas no bellas, dependiendo del punto de vista de la persona. Actualmente se puede hacer arte con cualquier cosa que se pretenda, y son muchos los modelos estéticos. Es por ello, que la influencia de su origen también influye en la percepción de su belleza y en la interpretación por parte del espectador.
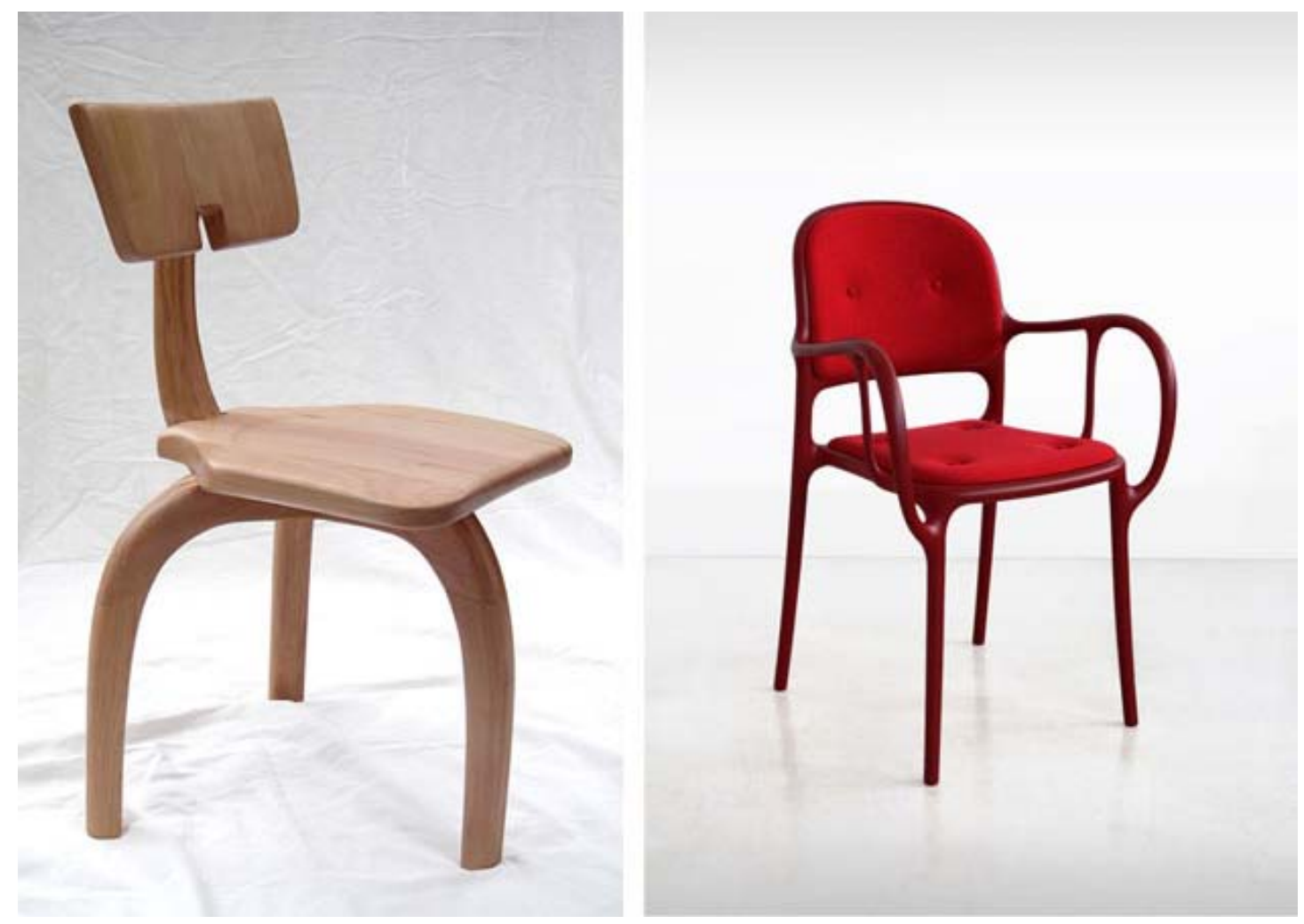

Fig. 1 (izda). Silla Mor de Martin Sabattini y Manuel Rapoport (Argentina 2004) ${ }^{7}$. Fig. 2 (dcha). Silla Milá de Jaime Hayón (España 2016) ${ }^{10}$.

Cada civilización tiene su propia belleza, una idea real de lo que es entendido como bello. La belleza china, la india o la negra, se interpretan diferentes dependiendo del receptor. Preguntarse la supremacía de una frente a la otra, no es más que una frase relativa que no contesta ni resuelve el problema, más que nada, porque puede parecer más bello o menos bello, pero a nivel personal'11.

Son las civilizaciones, y los orígenes los que hacen de la belleza propia un carácter en la forma de crear, apoyándose en unas reglas aprendidas con los años. Estos principios se basan en la herencia cultural y el mestizaje adquirido, entre otros. Este cruce cultural es asimilado por los diseñadores, que adquieren otras estéticas. Esto es fiel indicativo de una de las características de la identidad de Cultura Clásica Contemporánea. Ejemplo como el diseñador español Carlos Jimenez, que ha sabido mezclar sus raíces mediterráneas con el diseño escandinavo, y el recuerdo de una estética japonesa. 


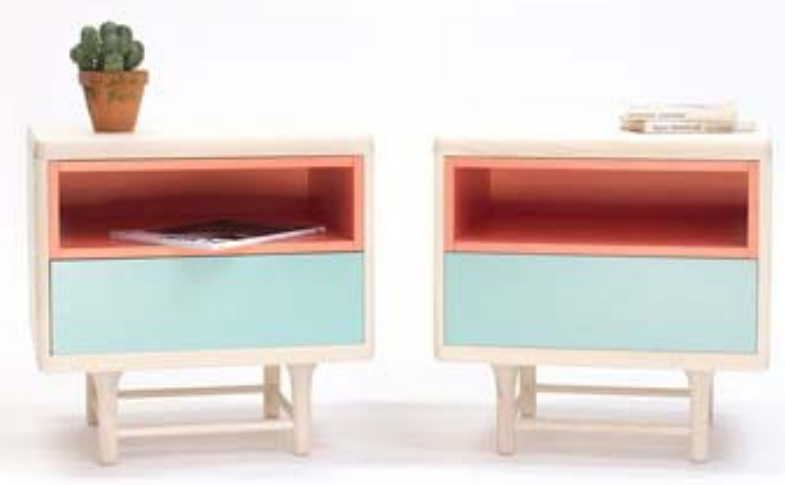

Fig. 3. Colección Kaaja de Carlos Jimenez (España 2015) ${ }^{12}$.

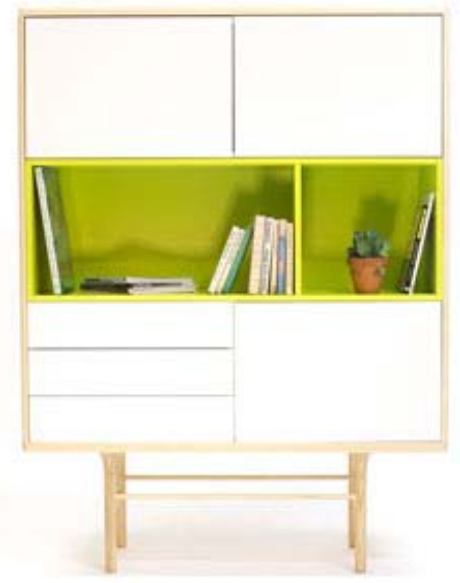

Fig. 4. Colección Kaaja de Carlos Jimenez (España 2015) ${ }^{13}$.

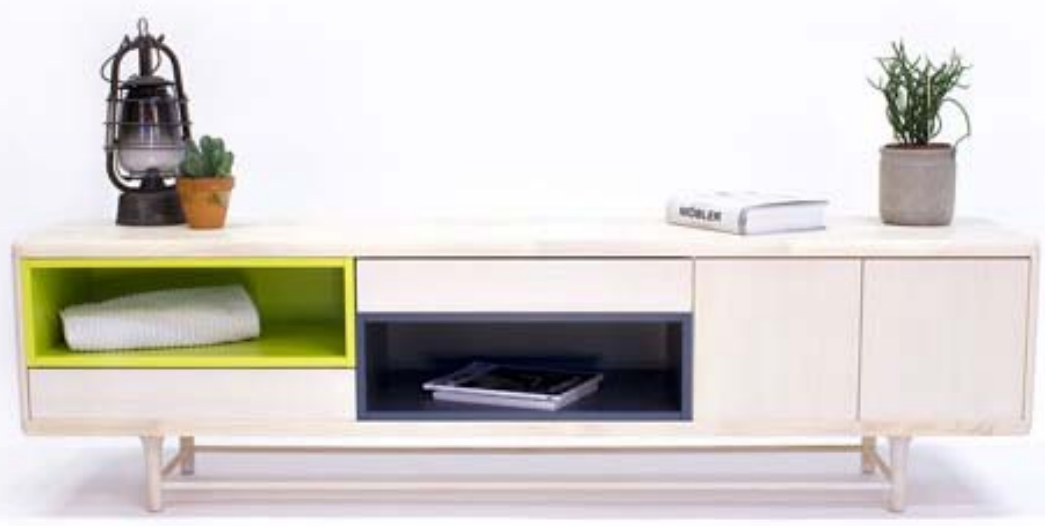

Fig. 5. Colección Kaaja de Carlos Jimenez (España 2015) ${ }^{14}$. 
Flusser ${ }^{15}$, recuerda como en el siglo XIX existía la opinión de que: Occidente es Occidente, Oriente es Oriente, y que ambos jamás pueden encontrarse (West is West and East is East, and never the twan shall meet). Basándose en que para Occidente lo más terrible es la muerte, mientras que para Oriente lo es la vida.

El transistor es un producto occidental, y un diseño japonés, así como la porcelana china basaba su fabricación en un diseño inglés, o como ya en el Imperio Romano se introdujeron culturemas del Extremo Oriente o culturemas helenísticos en China; así como los dragones mongoles, en las catedrales góticas, o los cascos de los dioses de la época de Alejandro en Angkor Watt.

El diseño no sigue a la función, sino a los mercaderes a bordo de sus barcos o a lo largo de las rutas de la seda. No hace falta invocar a Cristo o a Buda para comprender el transistor japonés. Basta con recordar la ocupación de los puertos de Japón por la flota de Estados Unidos o el espionaje industrial japonés en Europa y América durante el periodo de entreguerras. Y sin embargo, en cuanto empezamos a banalizar de este modo, tenemos la sensación de que se nos escapa de las manos el fenómeno que queríamos explicar ${ }^{16}$.

Es esta mezcla la que explica esa ciencia occidental en la forma oriental. Con ello estas dos identidades, más que alejarse la una de la otra forman un conjunto en que se nutren mutuamente. La creación a través del arte y del diseño es en sí una forma de expresión. En ellos se plasma la imaginación del artista, y se definen sus rasgos culturales y vinculaciones estéticas.

En el diseño gráfico, tenemos el ejemplo de Gonzalo Fargas ${ }^{17}$, quien ha sido gestor de la promoción de la propia identidad de la cultura. Este diseñador ha utilizado el diseño como medio de expresión en momentos en que no había cabida a otro tipo de manifestación. Este diseño proporcionó la oportunidad de mostrar la cultura y la sociedad que imperaba, reflejando la realidad, los movimientos sociales, económicos y políticos. Así el diseño logró ser conductor de los ojos de la calle, cuestión non grata en sectores donde el interés por la transparencia de ideas y la libertar de expresión no dejó de ser reprobado.

Los diseñadores han utilizado sus trabajos para poder dar a conocer sus ideas y hacer públicas las reivindicaciones de la sociedad ${ }^{18}$. Ellos, aun siendo poseedores de una identidad propia como individuo, poseen una marcada conciencia social y tienden a sintonizar e identificarse con los mismos intereses de la sociedad. Así es como reflejan en sus trabajos ese reclamo ya infundado, llenos de arte y creatividad, donde también se ve reflejada la identidad.

El diseño gráfico ha sido el difusor de los ideales y reivindicaciones en las que la sociedad se encontraba, así es como se ha utilizado a la gráfica como artefacto cultural ${ }^{19}$. Fue el cartel utilizado como demandante de una sociedad transgresora, o como muestra del momento socio-económico de la época y la ciudad.

...se promovió una visualidad asociada a un proyecto político, en sintonía con el mundo popular y a la vez, con la cultura de masas ${ }^{20}$.

Esta capacidad de identificación de la identidad de la sociedad, con el diseño gráfico, es usada por muchas marcas comerciales. La empresa $A E G^{21}$ ya inició sus programas integrales de identidad 
corporativa, no únicamente el estudio del diseño de signos, sino que se dedicó a mejorar y poner en valor los envases, etiquetas, presentaciones, los productos, el vestuario del personal, entre otros; y todo lo que de ella pudiese tener una imagen pública. La tipografía, el color, el estilo y todo lo que concierne a su diseño gráfico influyen notoriamente en la percepción del espectador.

El producto es identidad, siendo el reflejo de la propia empresa, y es en ella donde todo debe sustentar, originar y mantener un orden y coherencia, siendo uno de los primeros factores a tener en cuenta en la creación, planificación y/o modificación de una empresa o institución ${ }^{22}$.

Joan Costa contesta a la pregunta de Giovanna Rivero, buscando la diferencia entre los términos identidad corporativa e imagen corporativa, y este responde:

Identidad es un término que tiene un sentido cultural y estratégico. Es lo que hace que cada empresa sea diferente de todas las demás, única e irrepetible. Por tanto ésta es una cuestión esencial de gestión de la empresa, tal como lo son la administración, la organización, la producción, las relaciones con el personal, etc. Pero la identidad es algo invisible, y mucho menos variable que todo eso, y más sustancial en las organizaciones. Pensemos, para utilizar una analogía, en la identidad de un individuo (individuo viene de "indivisible", ser total). En su identidad biológica — su ADN, sus cromosomas- está todo el potencial de su futuro desarrollo en la vida. Este potencial cristalizará y será realizado a lo largo de su existencia por medio del contacto con los demás, la sociedad, la cultura y el entorno en que vive. Si cada individuo es capaz de descubrir su propia identidad, es decir, todo aquello que lo hace diferente de todos los demás individuos, único e irrepetible, y sabe acordar a esto sus proyectos personales, entonces cada uno se desarrollará en plenitud y será lo que efectivamente desea y puede $\operatorname{ser}^{23}$.

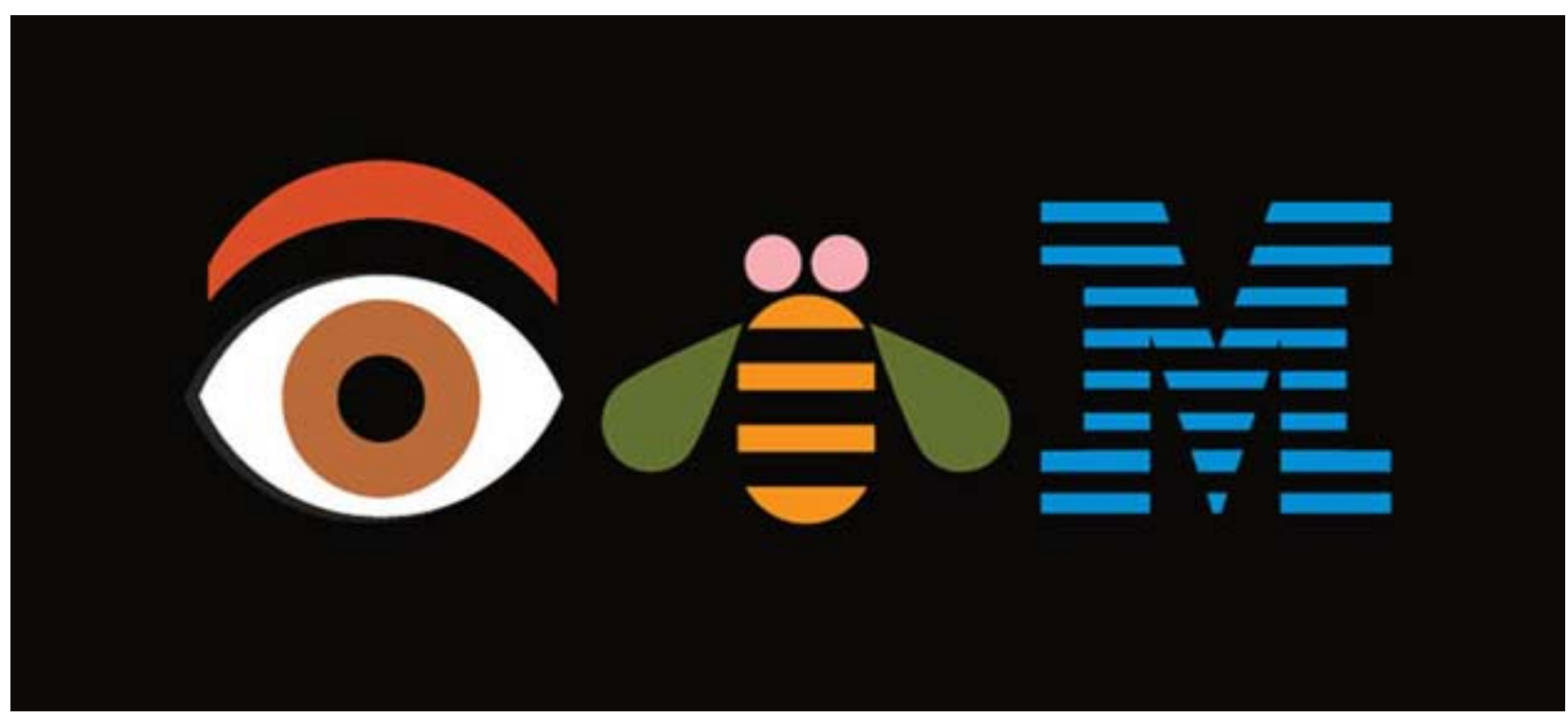

Fig 6. Cartel Eye-Bee-M para IBM, de Paul Rand (EE.UU. 1981).

Una de las figuras claves del diseño español de los años cincuenta, junto a Ricard Giralt Miracle, fue Manolo Prieto ${ }^{24}$. Ambos diseñadores contribuyeron destacadamente a sentar las bases de lo que entonces se denominaba arte publicitario. Partiendo de una estética ya planteada por los cartelistas e ilustradores de los años veinte y treinta, para marcar más tarde su propio estilo, más cercano a una estética internacional y alejada de la tendencia del momento de posguerra. 
Su obra más reconocida es la silueta para la valla del Toro de Osborne de 1956, un anuncio para el Grupo Osborne, que debido al éxito se ha convertido en patrimonio cultural y artístico de los pueblos de España. Ese toro recuerda a una fusión que Prieto supo sintetizar de arte, modernidad y tradición, mediante un toro libre en la naturaleza.

Otro diseñador gráfico importantísimo en las artes plásticas españolas es Pepe Cruz Novillo ${ }^{25}$, siendo suyos trabajos como los antiguos billetes del Banco de España, la imagen de Cercanías Renfe o los logos del PSOE o el Tesoro Público. Cruz Novillo crea también, entre otros muchos, el símbolo de Correos, representando la clásica trompeta de los carteros que utilizaban para avisar la llegada de las cartas a los vecinos, presente en muchas marcas de correos europeas, y que complementa con la corona real símbolo de España, dando un resultado de complejidad y sencillez a la vez.

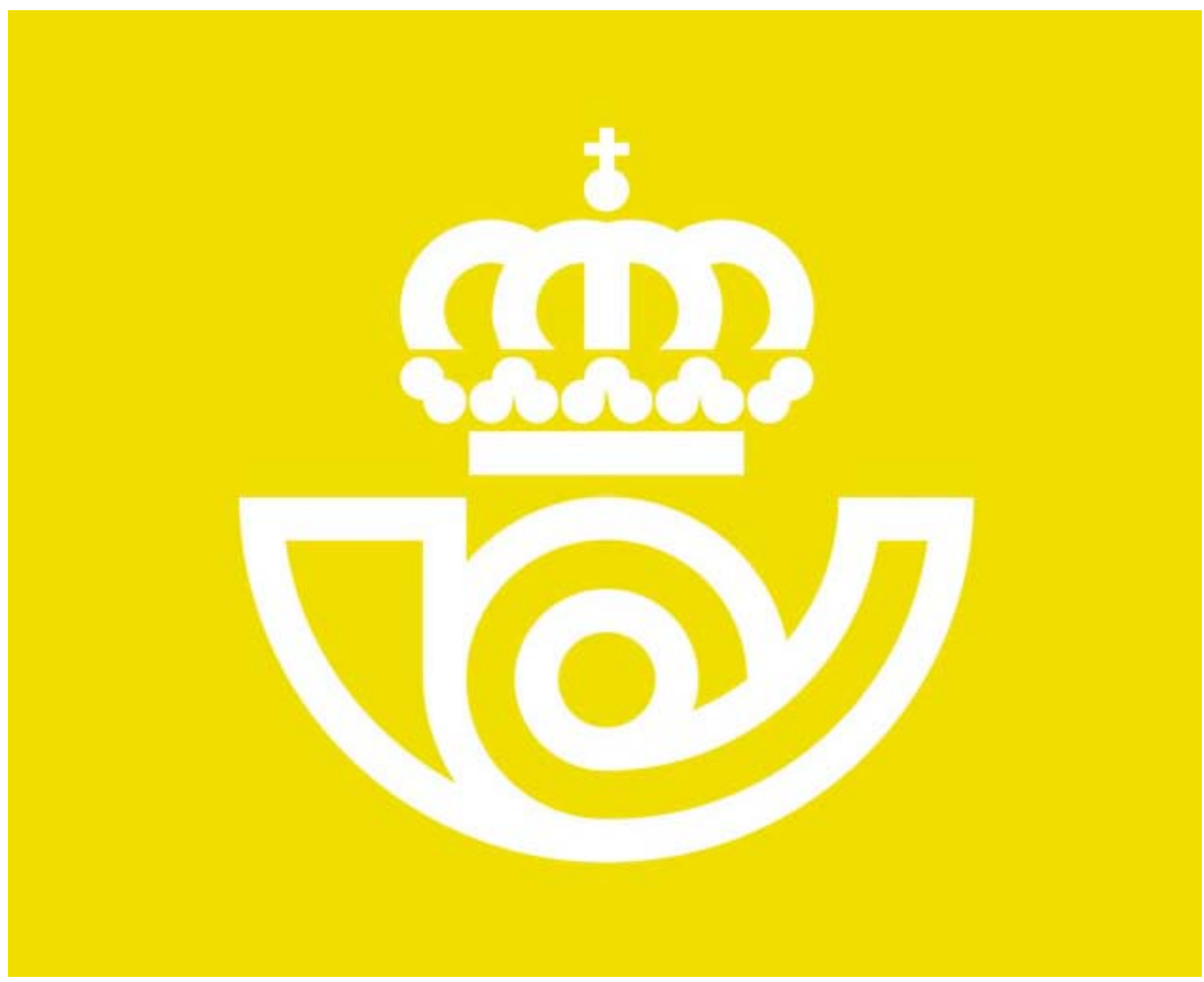

Fig 7. Símbolo para Correos, Pepe Cruz Novillo (España) ${ }^{\mathbf{2 6}}$.

Al igual que el símbolo, la tipografía es igual de importante en cuanto al trabajo del diseñador, y a como expresar esa identidad que quieren mostrar. El papel de los grabadores de punzones españoles de la segunda mitad del siglo XVIII ha sido muy importante, nombres como los dos grabadores que se formaron en la Real Academia de Bellas Artes de San Fernando ${ }^{27}$, Jerónimo Antonio Gil y Antonio Espinosa, creadores de sus respectivas tipografías con la denominación Ibarra, en honor al principal impresor de la época, con las que se imprimieron las ediciones más 
destacadas de la imprenta española de entonces y que son referentes indiscutibles en los que el diseño más actual se ha apoyado.

Cabe destacar esa importancia de los modelos en la caligrafía manual, para hacer los diseños tipográficos, donde Updike ${ }^{28}$ apunta que: "these types were modeled directly on the Spanish handwriting then considered ideal for documents or letters meant to be handsomely rendered".

En México el ilustrador José Guadalupe Posada ${ }^{29}$ destaca a finales del siglo XIX, considerado un "artista popular", donde sus obras reflejan hechos, fiestas y tradiciones del pueblo mexicano. Aprendió las técnicas de grabado en plomo y zinc, colaboró con el periódico La Patria llustrada y la Revista de México, y trabajó con Antonio Vanegas Arroyo, para posteriormente crear su propio taller litográfico, donde el trabajo del artista ya toma una dimensión mayor. La popularidad emanada de su proximidad a los sentimientos del pueblo, con un sentido del humor un tanto sátiro y cargado de dramatismo y calidad plástica, han hecho del artista uno de los más reseñables a nivel internacional. Sus temas artísticos se basaban en la dura crítica al gobierno y a su mando de poder, a las formas de la vida cotidiana, y el uso de sus famosas calaveras.

Pero si México se puede caracterizar por un logro a nivel gráfico, que ha marcado esa identidad mexicana, este fue el encargo del diseño gráfico mexicano de los Juegos Olímpicos de $1968^{30}$. Pedro Ramírez Vásquez, coordinador general de la competición, convocó al arquitecto mexicano Eduardo Terrazas y al diseñador americano Lance Wyman para la creación de la identidad visual de las olimpiadas. Ese resultado se considera hoy en día uno de los diseños más sorprendentes y atemporales. Era el propio Pedro Ramírez quien quería dotar a las olimpiadas de un carácter puramente mexicano, para que el extranjero visitante, ahondase en la cultura tan definida del país.

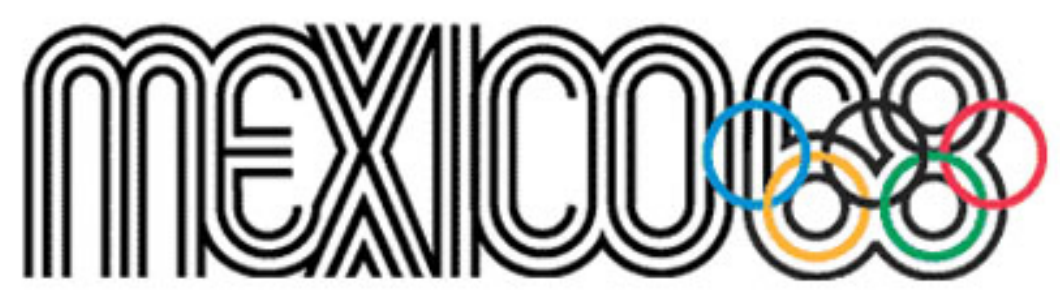

Fig 8. Identidad visual de las Olimpiadas de $1968^{31}$

Esa identidad tan marcada, reflejo de lo que ya se ha definido como la Cultura Clásica Contemporánea, también se ve en los jarrones de cristal de Murano, que nos recuerdan a Italia. Ya los artesanos del vidrio iniciaron la actividad en Oriente Medio y en Egipto ${ }^{32}$, para luego trasladarse 
a Italia (Murano) y a las zonas europeas más pobladas, donde encontraban el material para sus hornos (Alsacia, Bohemia, Lorena, Turingia y Segovia). Con la intención de salvaguardar las técnicas manuales y sus conocimientos, los artesanos mantenían un secretismo en su producción y en la manejabilidad de este material. Por tanto, ha sido a través de la herencia familiar como se han trasmitido esos conocimientos, procesos y modos de hacer.

Los años del auge del diseño italiano corresponden a la década de los cincuenta y sesenta, donde diseñadores como Ettore Sottsass, Andrea Branzi y Ugo La Piedra, hacen una búsqueda para definir el campo del diseño en la industria y el movimiento cultural y artístico de la época. Los empresarios gozaban de buena economía y la sociedad en sí estaba prosperando. Entonces aparece el Radical Design ${ }^{33}$, reclamando la necesidad de priorizar la creatividad, antepuesta a la función social y cultural, con la idea de un diseño creado más allá de los intereses empresariales. Ello contribuyó al diseño de piezas, cuanto menos divertidas, como el sillón Blow, diseñado conjuntamente por Gionatan de Pas, Donato D'urbino, Paolo Lomazzi y Carla Scolari en 1967, con un diseño atrevido y libertino. Recuerda al Pop Art y sus propuestas artísticas, pero con las técnicas industriales cada vez mejoradas por la evolución social y empresarial.

Es cuando Ettore Sottsass ${ }^{34}$ diseña en 1969 la famosa máquina de escribir Valentine, para Olivetti, con carcasa de color rojo en plástico ABS, y en menos cantidad, azul claro y gris, con el sentido de utilizarla en el tiempo libre y no tanto en la formalidad y profesionalidad del lugar de trabajo. En 1981 Sottsass, en la Feria del Mueble de Milán, presenta a Memphis ${ }^{35}$, una agrupación de diseñadores italianos, japoneses, españoles y estadounidenses implicados en un proyecto ambicioso a la vez que interesante, provocando la parte más creativa del diseño.

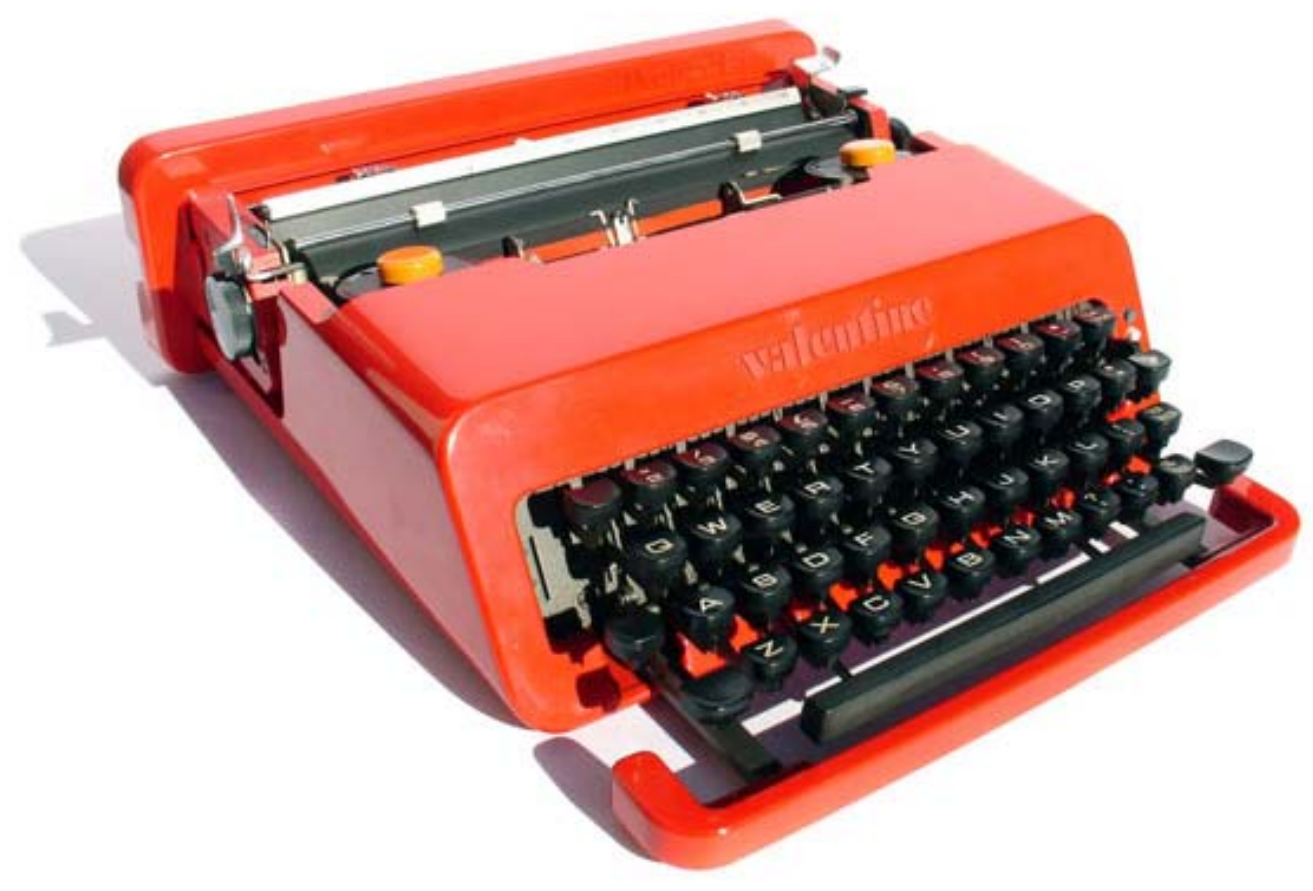

Fig 9. Máquina de escribir Valentine, Ettore Sottsass, $1969^{36}$. 


\section{Conclusiones}

La definición de la identidad propia de la Cultura Clásica Contemporánea queda materializada en los resultados de los procesos de diseño que realizan los artistas o los diseñadores. La identidad se plasma también en la similitud en sus formas, en la elección de sus colores, en los materiales y las técnicas creativas, y en la finalidad de ser un objeto para un consumidor que valora el carácter de la tradición.

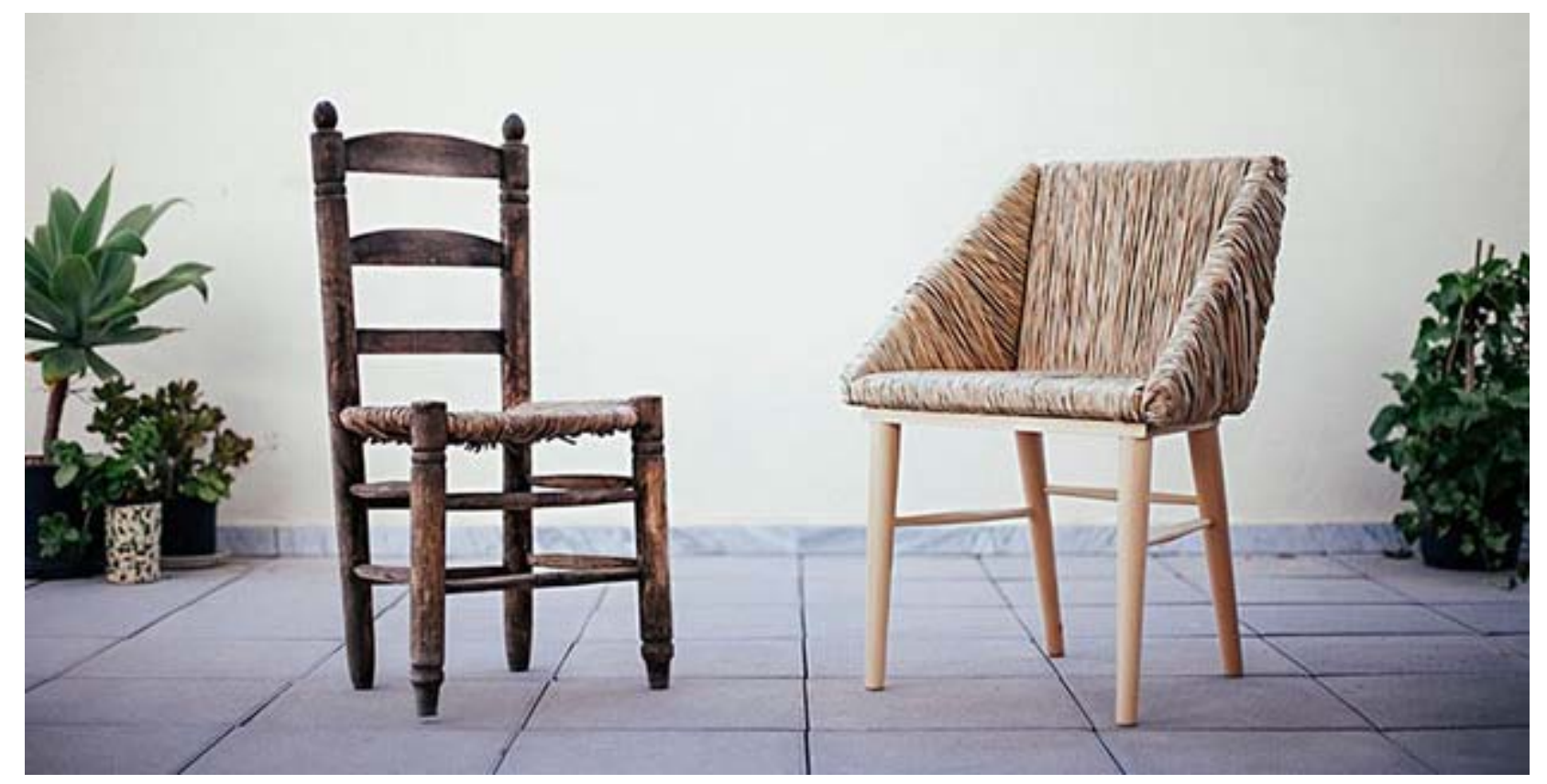

Fig 10. Silla La Fresca de Granada Barrero y Damián López (España). Premio del diseño de Andalucía $2015^{37}$.

Se trata de una identidad caracterizada por una capacidad de integrar los rasgos de otras culturas para involucrarlos en la suya propia, generando más riqueza cultural en ella. Posee un carácter acogedor y cercano a todas las personas, con un gran sentido en la virtud del mestizaje y en el aprovechamiento de este valor para dotar, desde su propia personalidad, a los objetos de valor estético.

Es una identidad amable, con toques irónicos, e involucrada en los problemas sociales, crítica y luchadora por causas justas y el bien común, usando los medios artísticos como medio de difusión y forma de exponer ese desacuerdo con lo establecido.

La amplia variedad de colores que se usan en la gráfica que abarca esa propia identidad es amplia, donde los naranjas, verdes, azules o amarillos son usados más frecuentemente que los colores fríos o austeros. Una gama cromática amplia, que no es única de los países latinos, como se pueda pensar en un primer momento, en los colores festivos brasileños o mexicanos, que dotan a sus ropas de diversos tonos. Es actual, el cartel para la serie Mad Men que ha realizado el diseñador Milton Glaser $^{38}$ en 2014, con una variedad de colores asombrosa, con unas líneas curvas y espontáneas, predominantes de esa identidad anunciada. Además de su origen norteamericano ha tenido siempre una estrecha relación con compañeros de origen latino, como el diseñador Félix Beltrán. 


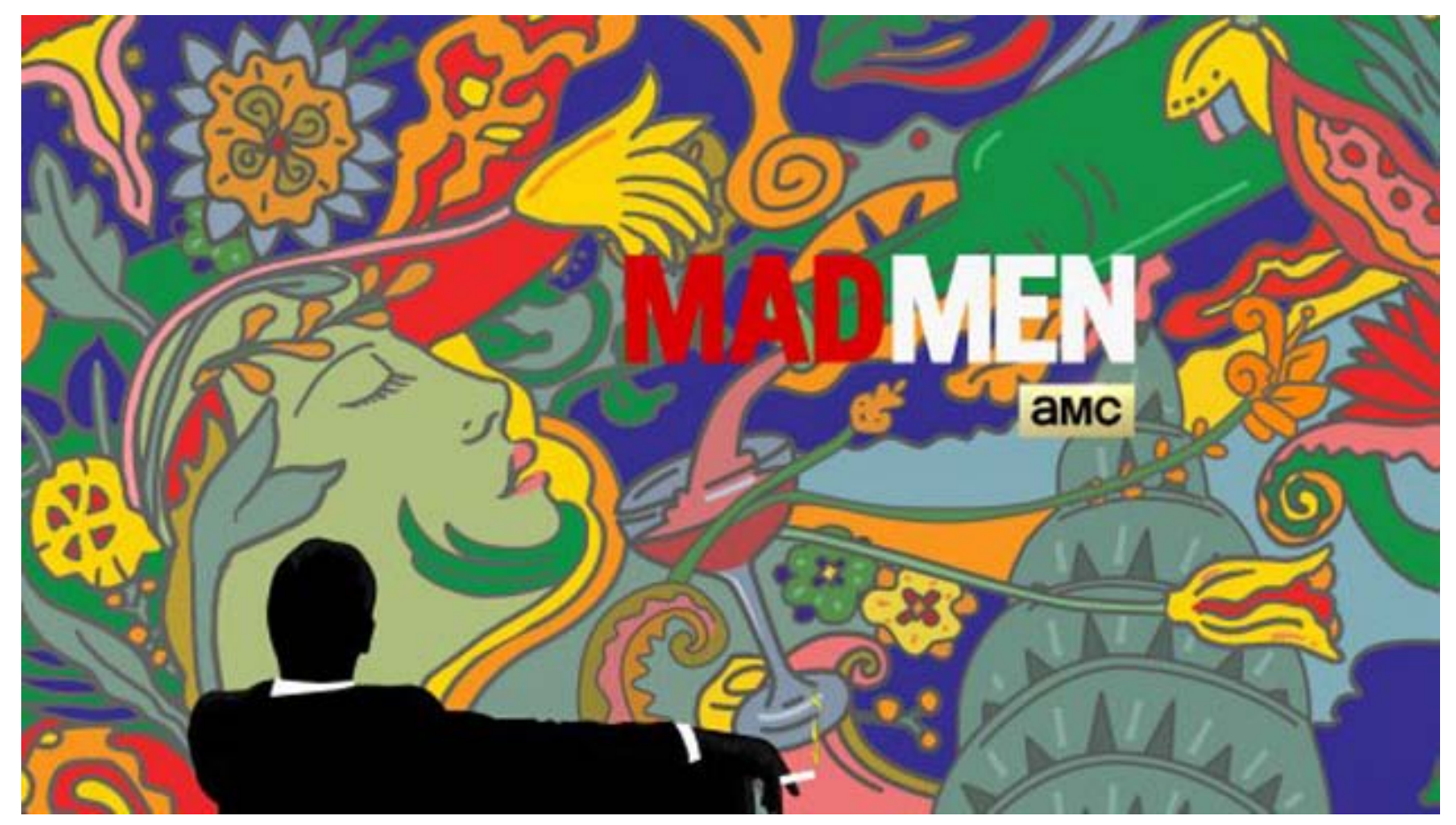

Fig 11. Portada serie Mad Men, Milton Glasser (EE.UU. 2014) ${ }^{39}$.

Es la identidad tan definida en el entorno, en los utilitarios, en las formas de ser y de hacer de las personas, una alternativa como estrategia frente a otros mercados y otras culturas. Es ventaja competitiva y sello definitorio de lo que la cultura ha mantenido y salvaguardado de forma continua, como legado y como orgullo heredado.

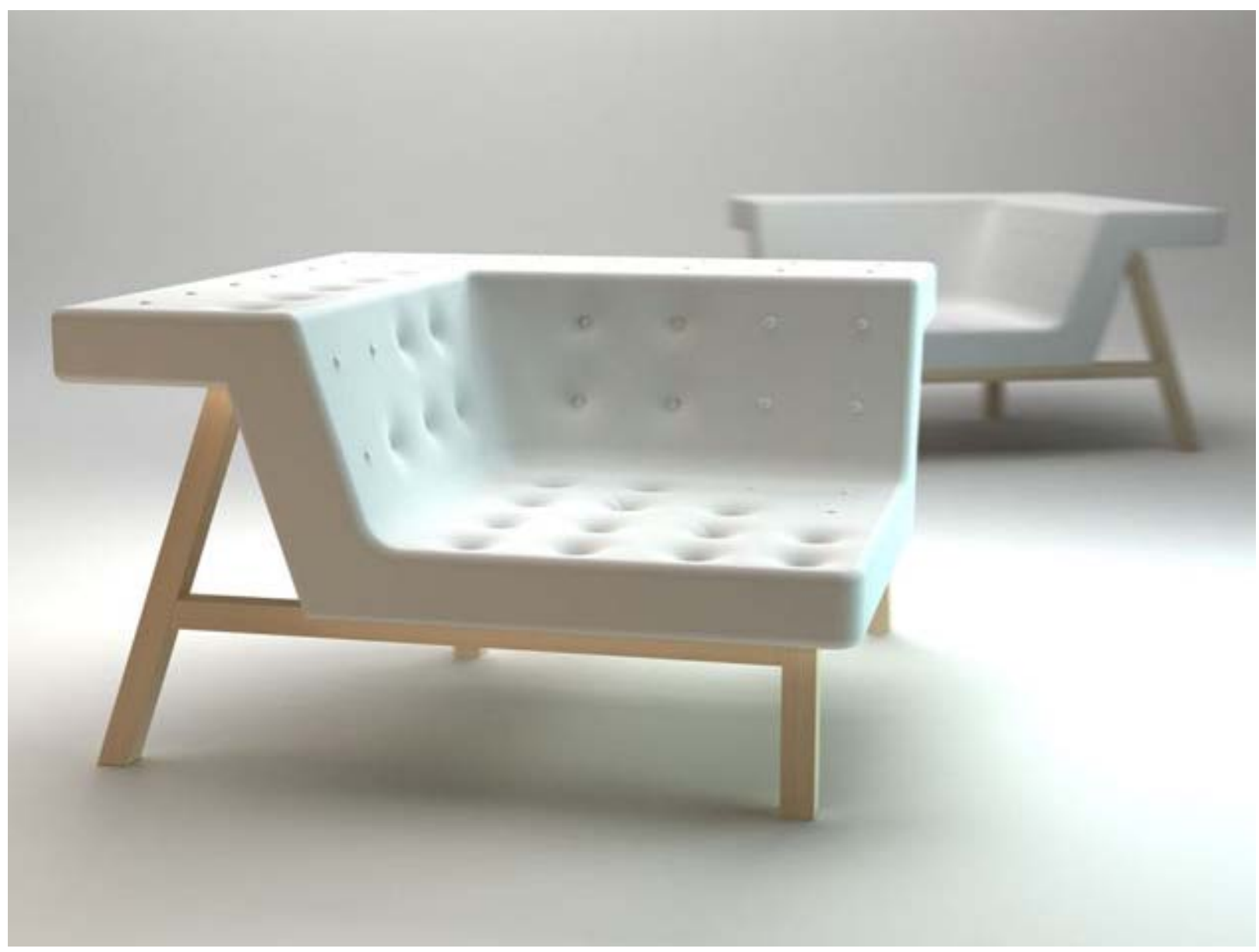

Fig 12. Sofá de Juan Cristobal Karich (Chile, 2010-2011) ${ }^{40}$. 
Son esos fundamentos los que definen a la Cultura Clásica Contemporánea, donde el mestizaje y la abertura de mente son los protagonistas. Es aquí donde nace su gran riqueza cultural, anclada en su tradición y su herencia.

El diseño en un país es sinónimo de innovación, y la acción en este ámbito aporta riqueza global al entorno. El diseñador hace uso de su talento y de las técnicas para generar valor, creando competencia, siendo el diseño centro y parte esencial de todo.

La emoción es fundamental para el consumidor, y el diseño hace conmover a la gente. Éste recrea recuerdos y rememora técnicas en desuso. Como la artesanía, a la que se recurre con mayor asiduidad para valorizar los diseños más contemporáneos. El uso de materiales naturales y sostenibles, también es cada vez más demandado por los diseñadores.

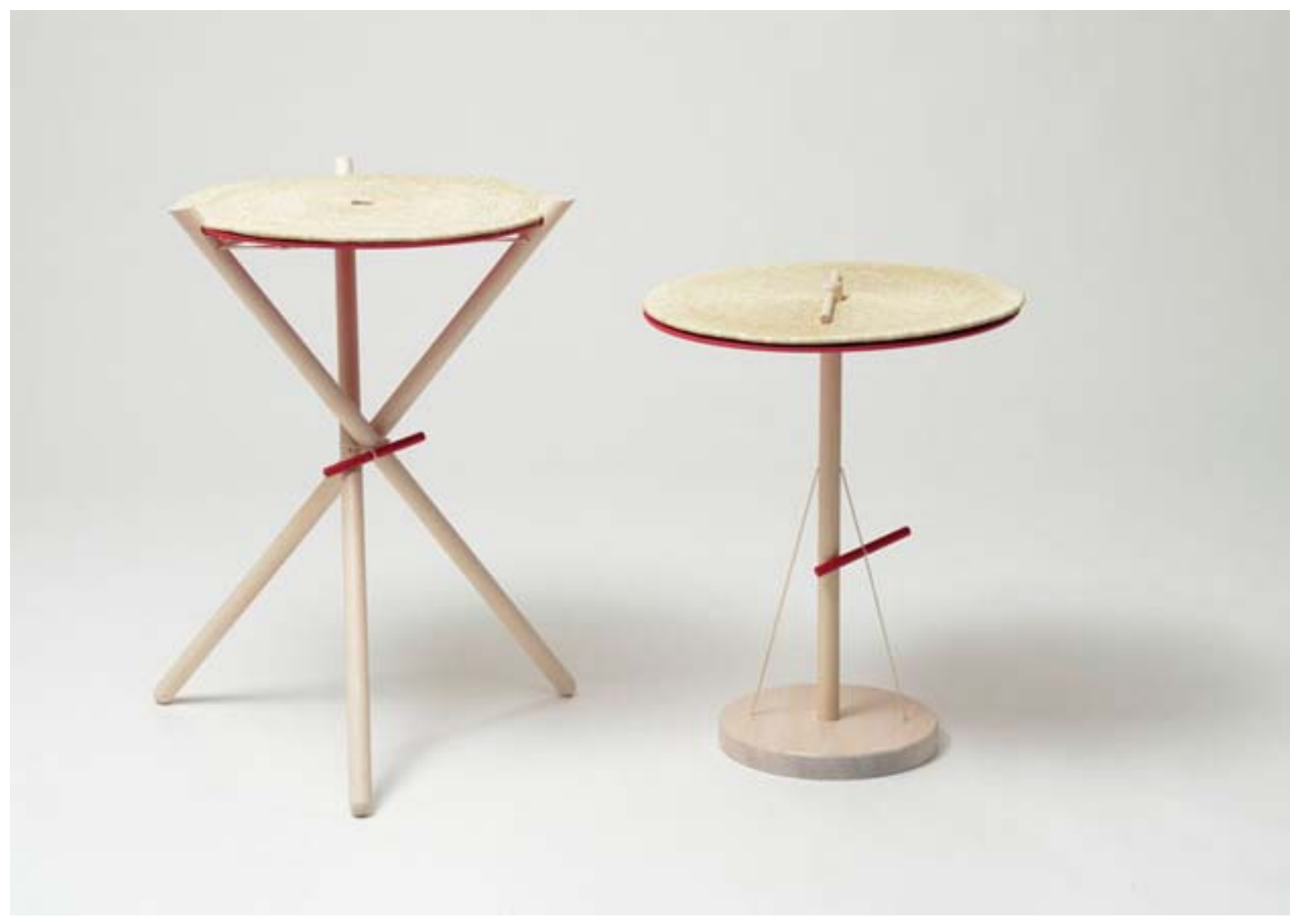

Fig 13. Coiling-the-unwanted de Juan Cappa (Colombia. Premio Lápiz de acero 2015) ${ }^{41}$.

La cultura, la identidad, la forma de ser, las costumbres, el carácter abierto, el mestizaje con otras culturas, son algunas características de la denominada Cultura Clásica Contemporánea. El uso de técnicas artesanales, dotando a los diseños industriales de humanismo, y dando resultados cercanos a la obra de arte, son los frutos de esa aplicación.

Es, por tanto, que el buen uso de esta identidad es clave para el correcto desarrollo de los países que abarca. La divulgación y ese interés por el mantenimiento de esta semejanza es apoyado por muchos sectores culturales, académicos y empresariales. Revistas especializadas, programas de doctorado, cursos, conferencias, programas de máster internacionales, ferias y congresos de 
diseño, donde los diseños y los objetos son reflejo de la personalidad de la cultura, son un escaparate actual de dicha identidad.
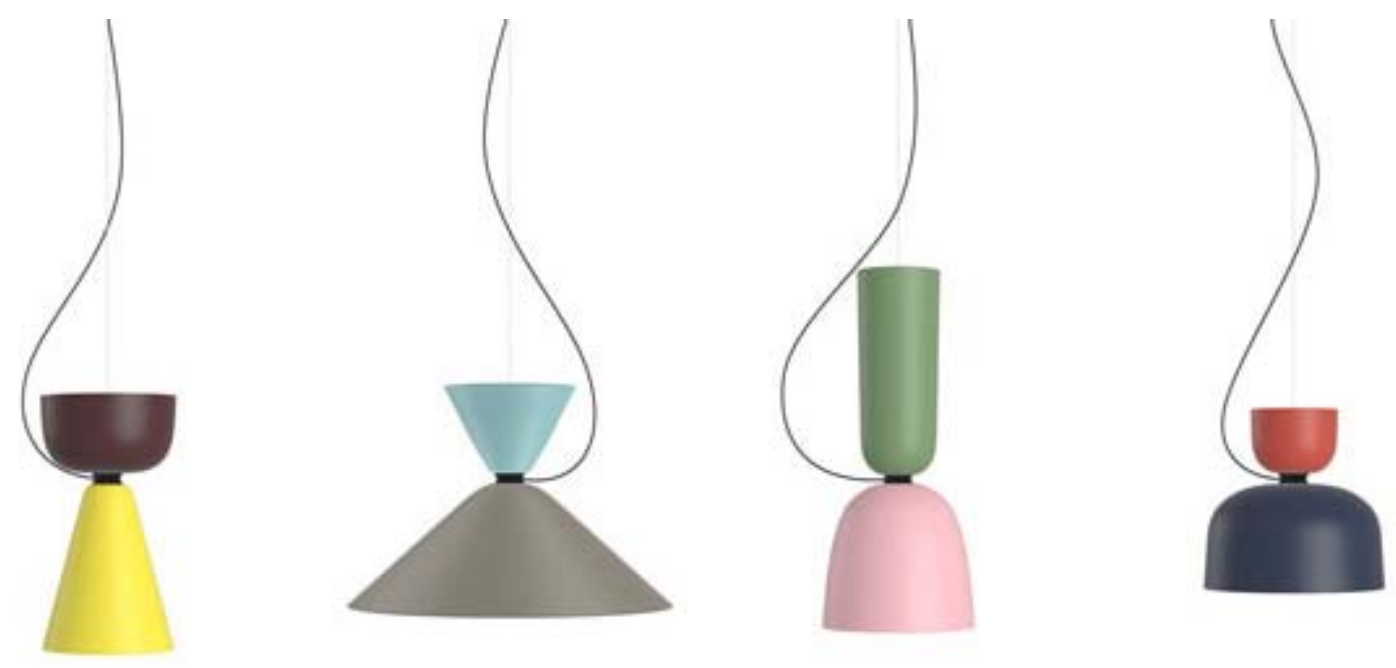

Fig 14. Alphabeta de Luca Nichetto (Italia, 2015) ${ }^{42}$.

${ }^{1}$ Máster interuniversitario en Representación y Diseño en Ingeniería y Arquitectura (Universidad de Málaga, Córdoba y Almería) y Graduada en Ingeniería en Diseño industrial y Desarrollo del Producto (Universidad de Málaga). Doctorando en Diseño Industrial. Correo-e: gonzalezmirandacarolina@gmail.com

${ }^{2}$ GARCÍA GARRIDO, S. Identidad del Diseño de la Cultura Clásica Contemporánea ante el humanismo en la era de las redes interpersonales [Discurso del miembro electo Dr. D. Sebastián García Garrido leído en el Acto de su Recepción Pública], Sociedad Erasmiana de Málaga 2014.

3 GARCÍA GARRIDO, S. Op. cit.

${ }^{4}$ OTERO, J. De Bogotá a Rosario. La lengua española y la política regional de España en América Latina. Madrid, Real Instituto Elcano, DT núm. 36/2004, p. 19..

5 GARCÍA GARRIDO, S. Op. cit.

${ }^{6}$ BECK, H. "América latina como encuentro cultural creativo", en Invenio, noviembre 2005.

7 <http://designopatagonia.com.ar/>(05.12.2016)

${ }^{8}$ BELTRÁN, F. Confesiones sobre el diseño gráfico [Conferencia $6^{\circ}$ Encuentro BID Enseñanza y Diseño], Madrid (27.11.2015)

9 MUNARI, B. Diseño y comunicación visual. Contribución a una metodología proyectual. Gustavo Gili, Barcelona 2016, p. 66.

$10<$ www.hayonstudio.com> (25.02.2016)

${ }^{11}$ MUNARI, B. en Arte ¿? Diseño, Gustavo Gili, Barcelona 2003.

12 <http://www.carlosjimenezdesign.com/> (03.03.2016)

13 Ibidem.

14 Ibidem.

${ }^{15}$ FLUSSER, V. Filosofía del Diseño, Editorial Síntesis, 1999, pp. 83-89.

16 Ibidem.

${ }^{17}$ ARGAS, G. prólogo del libro de F. TABORDA/J.WIEDEMAN, Latin American Design Graphic, Taschen, Köln 2008, p. 6.

${ }^{18}$ FARGAS, G. Op. cit. 
${ }^{19}$ VERGARA-LEYTON, E./GARRIDO-PEÑA, C./UNDURRAGA-PUELMA, C. "La gráfica como artefacto cultural. Una aproximación semiótica al cartel social en Chile" en Arte, individuo y Sociedad, núm. 26 (2), Madrid 2014, pp. 271285.

${ }^{20}$ Ibidem.

${ }^{21}$ GARCÍA GARRIDO, S. "Diseño como materialización de la identidad", en i+Diseño, vol. 3, Málaga 2010, pp. 2442.

22 GARCÍA GARRIDO, S. "Conceptos de identidad e imagen corporativa en el ámbito institucional", en revista Convergencias, núm. 5, 2010.

${ }^{23}$ COSTA, J. Diseñar para los ojos, Costa Punto Com, Barcelona 2008, p. 87.

${ }^{24}$ GIL, M. Pioneros del diseño gráfico en España, Index Book, 2007.

25 JUNCO, M.A. "Cruz Novillo; historia del diseño" en revista i+Diseño, vol. 2, Málaga 2010, pp. 85-95.

${ }^{26} \mathrm{http} / / /$ www.cruznovillo.com/(06.02.2015)

${ }^{27}$ GARCíA GARRIDO, S. Elogio de la Lengua Española y las Artes del Libro. Tipometrías, i+Diseño, Málaga 2014, p. 62.

${ }^{28}$ UPDIKE, DB. Printing Types. Their history, Forms and Use, Harvard University Press, 1922, vol. II, p. 87.

29 GARONE GRAVIER, M. "La tipografía en la obra de José Guadalupe Posada", en Invetio, la génesis de la cultura universitaria en Morelos, núm. 14, 2011, pp.76-83.

${ }^{30}$ BREWSTER, K. "Implicaciones políticas y culturales de las Olimpiadas de México 1968", en Razón y palabra, núm. 69, 2009.

31 http://www.edemx.com/(02.03.2015)

${ }^{32}$ RAMBERRIM, J. "Vidrio: arte, industria, sociedad", en FabriKart, arte, tecnología, industria, sociedad, 2001.

${ }^{33}$ GAY, A./SAMAR, L. El diseño industrial en la historia, Ediciones Tec, Argentina, Córdoba 2007, p. 113.

${ }^{34}$ FIEL, C./FIEL, P. El diseño industrial de la A a la Z, Taschen, Köln 2001.

${ }^{35}$ FITOUSSI, B. Memphis, Editorial H. Kliczkowski, 2003.

36 http://www.catalogodiseno.com/(03.02.2015)

37 http://www.granadabarrero.com/(03.03.2016)

38 www.miltonglaser.com(01.11.2014)

39 Ibidem.

40 http://www.karich.cl/(05.03.2016)

${ }^{41}$ www.juancappa.com(05.03.2016)

42 http://nichettostudio.com/ (08.01.2016)

\section{BIBLIOGRAFÍA}

ARAMBERRIM, J. "Vidrio: arte, industria, sociedad", en FabriKart, arte, tecnología, industria, sociedad, 2001.

BECK, H. "América latina como encuentro cultural creativo", en Invenio, noviembre 2005.

BELTRÁN, F. Confesiones sobre el diseño gráfico, [Conferencia $6^{\circ}$ Encuentro BID Enseñanza y diseño], Madrid (27.11.2015)

BREWSTER, K. "Implicaciones políticas y culturales de las Olimpiadas de México 1968", en Razón y palabra, núm. 69, 2009.

COSTA, J. Diseñar para los ojos, Costa Punto Com, Barcelona 2008.

FARGAS, G. prólogo del libro de F. TABORDA y J.WIEDEMAN, Latin American Design Graphic, Taschen, Köln 2008.

FIEL, C./FIEL, P. El diseño industrial de la A a la Z, Taschen, Köln 2001. 
FITOUSSI, B. Memphis, Editorial H. Kliczkowski, 2003.

FLUSSER, V. Filosofía del Diseño, Editorial Síntesis, 1999.

GARCÍA GARRIDO, S. "Conceptos de identidad e imagen corporativa en el ámbito institucional", en revista Convergencias, núm. 5, 2010.

— "Diseño como materialización de la identidad", en i+Diseño, vol. 3, Málaga 2010.

— Elogio de la Lengua Española y las Artes del Libro. Tipometrías, i+Diseño, Málaga 2014.

- Identidad del Diseño de la Cultura Clásica Contemporánea ante el humanismo en la era de las redes interpersonales [Discurso del miembro electo Dr. D. Sebastián García Garrido leído en el Acto de su Recepción Pública], Sociedad Erasmiana de Málaga, 2014.

GARONE GRAVIER, M. "La tipografía en la obra de José Guadalupe Posada", en Inventio, la génesis de la cultura universitaria en Morelos, núm. 14, 2011.

GAY, A./SAMAR, L. El diseño industrial en la historia, Ediciones Tec, Córdoba, Argentina 2007, p. 113.

GIL, M. Pioneros del diseño gráfico en España, Index Book, 2007.

JUNCO, M.A. "Cruz Novillo; historia del diseño" en i+Diseño, vol. 2, Málaga 2010.

MUNARI, B. Diseño y comunicación visual. Contribución a una metodología proyectual. Gustavo Gili, Barcelona 2016.

OTERO, J. De Bogotá a Rosario. La lengua española y la política regional de España en América Latina. Madrid, Real Instituto Elcano, DT No 36/2004.

UPDIKE, D.B. Printing Types. Their history, Forms and Use, vol. II, Harvard University Press, 1922.

VERGARA-LEYTON, E./GARRIDO-PEÑA, C./UNDURRAGA-PUELMA, C. "La gráfica como artefacto cultural. Una aproximación semiótica al cartel social en Chile" en Arte, individuo y Sociedad, Madrid 2014, núm. 26 (2).

Revista internacional de investigación, innovación y desarrollo en Diseño • ISSN 1889-433 x

Grupo de investigación Lenguaje Visual y Diseño Aplicado • Plan Andaluz de Investigación • E. Politécnica S. • Universidad de Málaga 